\title{
Involvement of Reactive Oxygen Species in Sonodynamically Induced Apoptosis by 4-Formyloximeetylidene-3-Hydroxyl-2-Vinyl-Deuterio- Porphynyl (IX)-6-7-Diaspartic Acid (ATX-S10)
}

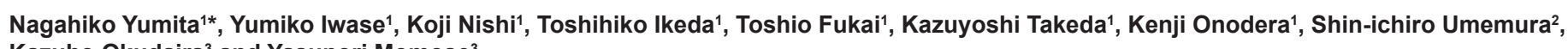
Kazuho Okudaira ${ }^{3}$ and Yasunori Momose ${ }^{3}$

${ }^{1}$ School of Pharmacy, Yokohama College of Pharmacy, 601, Matano-cho, Totsuka-ku, Yokohama, Kanagawa 245-0066, Japan

${ }^{2}$ Department of Electrical and Communication Engineering, Tohoku University, Aoba 6-6-05, Aramaki, Aoba-ku, Sendai 980-8579, Japan

${ }^{3}$ School of Pharmaceutical Sciences, Toho University, 2-2-1 Miyama, Funabashi, Chiba 274-8510, Japan

\section{Abstract}

Background: In this study, we investigated the induction of apoptosis by ultrasound in the presence of the photochemically active chlorine, 4-formyloximeetylidene-3-hydroxyl-2-vinyl-deuterio-porphynyl (IX)-6-7-diaspartic acid (ATX-S10).

Methods: HL-60 cells were exposed to ultrasound for up to 3 min in the presence and absence of ATX-S10, and the induction of apoptosis was examined by analyzing cell morphology, DNA fragmentation, and caspase-3 activity.

Results: Cells treated with $80 \mu \mathrm{M}$ ATX-S10 and ultrasound clearly showed membrane blebbing and cell shrinkage, whereas significant morphologic changes were not observed in cells exposed to either ultrasound or ATX-S10 alone. Also, DNA ladder formation and caspase-3 activation were observed in cells treated with both ultrasound and ATX-S10 but not in cells treated with ultrasound or ATX-S10 alone. In addition, the combination of ATX-S10 and the same acoustical arrangement of ultrasound substantially enhanced nitroxide generation by the cells. Sonodynamically induced apoptosis, caspase-3 activation, and nitroxide generation were significantly suppressed by histidine.

Conclusions: These results indicate that the combination of ultrasound and ATX-S10 induces apoptosis in HL-60 cells. The significant reduction in sonodynamically induced apoptosis, nitroxide generation, and caspase-3 activation by histidine suggests active species such as singlet oxygen are important in the sonodynamic induction of apoptosis.

General significance: The results reported in this paper are experimental, but they significantly support the possibility of sonodynamic treatment for cancer using the induction of apoptosis.

Keywords: Apoptosis; Sonodynamic therapy; Ultrasound; ATX-S10; HL-60 cells; Reactive oxygen; Caspase-3

\section{Introduction}

Ultrasound has a tissue attenuation coefficient that allows it to penetrate intervening tissues and reach internal targets without losing the ability to focus energy into small volumes. This is a unique advantage over electromagnetic modalities such as laser light and microwaves for the noninvasive treatment of internal tumors. Although the use of ultrasound for tumor treatment has been fairly well investigated with respect to the thermal effects of ultrasound absorption [1,2], only a few groups have reported its nonthermal effects, such as potential sonochemical effects [3-7].

Recently, we found that photochemically active porphyrins such as hematoporphyrin, Porfimer Sodium (PF) and a gallium porphyrin complex, 7,12-bis(1-decyloxyethyl)-Ga(III)-3,8,13,17-tetramethylporphyrin 2,18-dipropionyl diaspartic acid (ATX-70) can induce significant cell damage when activated by ultrasound $[8,9]$. When implanted murine tumors are treated after the administration of such chemicals, tumor growth is significantly inhibited at intensity where ultrasound alone shows only a slight inhibitory effect [10-12]. Therefore, photochemically active porphyrins may be useful for sensitizing tumors to ultrasound. We have proposed that this potential modality be called "sonodynamic therapy" [13].

4-formyloximeetylidene-3-hydroxyl-2-vinyl-deuterio-porphynyl (IX)-6-7-diaspartic acid (ATX-S10; Figure 1) shows a much longer phosphorescence lifetime than $\mathrm{PF}$ or hematoporphyrin derivative

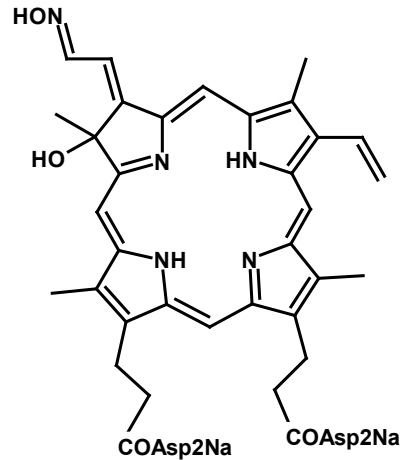

Figure 1: Chemical structure of ATX-S10.

*Corresponding author: Nagahiko Yumita, School of Pharmacy, Yokohama College of Pharmacy, 601, Matano-cho, Totsuka-ku, Yokohama, Kanagawa 2450066, Japan, Tel: +81-45-859-1300; E-mail: n.yumita@hamayaku.ac.jp

Received November 23, 2011; Accepted December 13, 2011; Published December 15, 2011

Citation: Yumita N, Iwase Y, Nishi K, Ikeda T, Fukai T, et al. (2011) Involvement of Reactive Oxygen Species in Sonodynamically Induced Apoptosis by 4-Formyloximeetylidene-3-Hydroxyl-2-Vinyl-Deuterio-Porphynyl(IX)-6-7-Diaspartic Acid (ATX-S10). Biochem \& Anal Biochem S2-001. doi:10.4172/2161-1009.S2-001

Copyright: (C) 2011 Yumita N, et al. This is an open-access article distributed under the terms of the Creative Commons Attribution License, which permits unrestricted use, distribution, and reproduction in any medium, provided the original author and source are credited. 
Citation: Yumita N, Iwase Y, Nishi K, Ikeda T, Fukai T, et al. (2011) Involvement of Reactive Oxygen Species in Sonodynamically Induced Apoptosis by 4-Formyloximeetylidene-3-Hydroxyl-2-Vinyl-Deuterio-Porphynyl(IX)-6-7-Diaspartic Acid (ATX-S10). Biochem \& Anal Biochem S2-001. doi:10.4172/2161-1009.S2-001

[14]. This long phosphorescence lifetime can be a great advantage for the efficient photochemical generation of singlet oxygen. It has been reported that ATX-S10 is much less toxic than ATX-70. In addition, in mice, the lethal dose of ATX-S10 is much higher than that of ATX70. Furthermore, like some porphyrins, ATX-S10 is preferentially retained by tumors tissues. Nakajima et al [14] showed that ATX-S10 accumulated in colon 26 tumor tissues after intravenous injection, allowing significant destruction of the tumor tissue upon irradiation with pulsed laser light, suggesting that ATX-S10 is an effective photosensitizer for use in photodynamic therapy. In the previous paper, we reported ATX-S10 is ultrasonically activated and shows antitumor effect on isolated tumor cells and solid tumor [16].

Apoptosis can be initiated by a wide variety of intracellular and extracellular stimuli and is a mechanism for the removal of unnecessary, aged, or damaged cells. Cells undergoing apoptosis exhibit characteristic morphological changes, including initial shrinkage, followed by widespread membrane blebbing, chromatin condensation, and DNA fragmentation. The cell further disassembles into membraneenclosed vesicles called apoptotic bodies that are rapidly taken up and digested by neighboring cells and phagocytes [17-19].

Recently, ultrasonic exposure has been shown to trigger apoptosis in both normal and malignant cells. Ultrasound-induced apoptotic cell death has been confirmed in K562, HL-60, and U937 leukemia cells [2024]. In addition, contrast agents are reported to enhance ultrasonically induced apoptosis [25], but only a few report on the effects of sonochemically active agents on ultrasonically induced apoptosis have been published [26]. Therefore, in this study, we examined whether the sonochemically active porphyrin ATX-S10 can enhance ultrasonically induced apoptosis in HL60 cells.

\section{Materials and Methods}

\section{Chemicals}

ATX-S10 was a generous gift from Toyo Hakka Kogyo (Okayama, Japan). Trypan blue, agarose, RNase A, and proteinase $\mathrm{K}$ were purchased from Wako (Tokyo, Japan). Histidine, superoxide dismutase (SOD), mannitol, Ethidium bromide, 2,2,6,6-Tetramethyl-4piperidone(TMPone), 2,2,6,6-tetramethyl-4- piperidone-N-oxyl, and 2,2,6,6-tetramethyl-4-piperidol-N-oxyl were purchased from Sigma ( $\mathrm{St}$ Louis, MO, USA). All the other reagents were of analytical grade.

\section{Cell culture}

Human promyelocytic leukemia HL-60 cells were obtained from the Riken Gene Bank (Tokyo, Japan). Cells were maintained in RPMI 1640 medium supplemented with $10 \%$ heat-inactivated fetal bovine serum (GIBCO BRL, Tokyo, Japan), 100U/ml penicillin G, $100 \mu \mathrm{g} / \mathrm{ml}$ streptomycin, and $2 \mathrm{mM}$ glutamine (Sigma-Aldrich) in an atmosphere of $5 \% \mathrm{CO} 2$ in humidified air at $37^{\circ} \mathrm{C}$.

\section{Ultrasound apparatus}

The apparatus for ultrasonic exposure is shown schematically in Figure 2. The ultrasound transducer uses a piezoelectric ceramic disk $24 \mathrm{~mm}$ in diameter and was driven at its resonance frequency (1.93 $\mathrm{MHz}$ ). Before exposure, the cells were harvested and washed twice in phosphate-buffered saline (PBS, pH 7.4). HL-60 cells were washed, resuspended at a concentration of $1 \times 106$ cells $/ \mathrm{ml}$ in $2.5 \mathrm{ml}$ of RPMI 1640 (serum free), and transferred into a cylindrical $16 \times 125 \mathrm{~mm}$ polystyrene tissue culture tube (Corning, Corning, NY, USA) for exposure to ultrasound. A polystyrene tissue culture tube was suspended $35 \mathrm{~mm}$

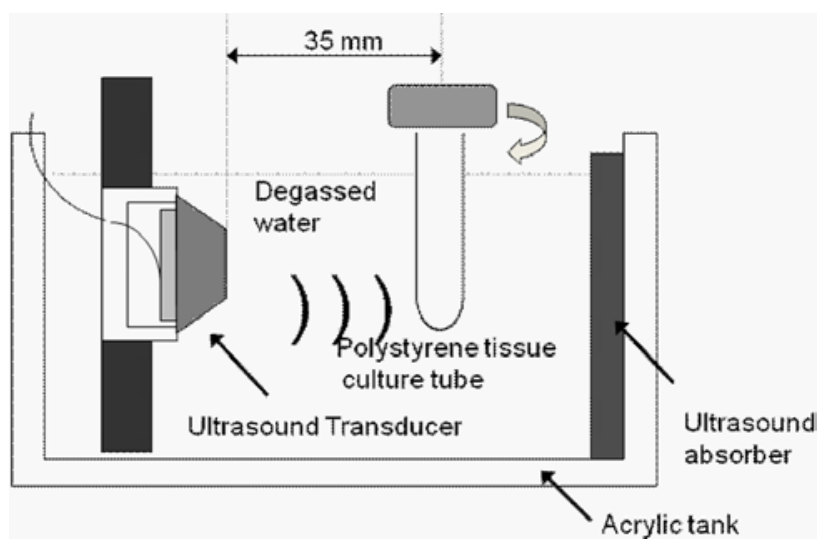

Figure 2: Diagram of the ultrasonic exposure apparatus.

away from the surface of the plane-wave transducer in degassed water, and insonated at $37^{\circ} \mathrm{C}$. Immediately before exposure, ATX S-10 was added to the cell suspension. During exposure, the tube was rotated at $60 \mathrm{rpm}$ by a synchronous motor to improve mixing and to provide a uniform exposure. HL-60 cells were exposed to ultrasound for up to 3 min in the presence and absence of PF. The samples treated with PF alone were kept in the same position for the same period as the ultrasonic exposure. Ultrasonic output from the transducer was evaluated in degassed water by placing the axis of the transducer horizontally. The output acoustic power was calibrated by measuring the radiation force on a 2-mm-thick hollow aluminum plate with an area of $20 \times 28 \mathrm{~mm}$, suspended at an angle of $45^{\circ}$ to the axis. Its horizontal projection was therefore $20 \mathrm{~mm} \times 20 \mathrm{~mm}$. The ultrasonic intensity was calculated by dividing the measured acoustic power by the projected area. The temperature rise in $2.5 \mathrm{ml}$ RPMI 1640 in the container during a 5-min exposure at the highest ultrasonic intensity used in the experiments was less than $1^{\circ} \mathrm{C}$. After the treatment procedure, the medium was replaced with fresh RPMI 1640 with $10 \%$ FBS and the cells was incubated in an atmosphere humidified with $5 \% \mathrm{CO} 2$ at $37^{\circ} \mathrm{C}$ for 6 hours before apoptosis induction was evaluated

\section{Evaluation of apoptosis and cell damage}

Apoptosis is characterized by morphological changes such as membrane blebbing, cell shrinkage, and disassembly of the cell into apoptotic bodies. During or after the ultrasound treatment, HL-60 cells were examined using a phase contrast inverted microscope (Olympus, Tokyo, Japan) at $400 \times$ magnification. The viability of the treated cells was determined by staining of the cells with trypan blue immediately after the treatment. The fraction of apoptotic cells was determined by counting the number of unstained cells showing morphological changes on a hemocytometer glass plate. The integrity was checked right before each series of treatment, and cell suspensions with integrity above $99 \%$ were used. This number of intact cells before treatment was regarded as the standard for the integrity determination after each treatment.

\section{Electrophoretic analysis of DNA fragmentation}

After experimental treatments, the cells were harvested, washed in PBS (pH 7.4), and lysed in $100 \mu \mathrm{l}$ of $0.1 \mathrm{M}$ phosphate-citrate buffer. Following lysis, the samples were centrifuged at $16000 \times \mathrm{g}$ for $5 \mathrm{~min}$. Then, supernatants were treated with $200 \mu \mathrm{g} / \mathrm{ml}$ DNase-free RNase at $37^{\circ} \mathrm{C}$ for 1 hour, followed by $1 \mu \mathrm{g} / \mathrm{ml}$ proteinase $\mathrm{K}$ at $50^{\circ} \mathrm{C}$ for 1 hour. The samples were separated by electrophoresis on $1.5 \%(\mathrm{w} / \mathrm{v})$ agarose gels containing $1 \mu \mathrm{g} / \mathrm{ml}$ ethidium bromide. Separated DNA fragments 
Citation: Yumita N, Iwase Y, Nishi K, Ikeda T, Fukai T, et al. (2011) Involvement of Reactive Oxygen Species in Sonodynamically Induced Apoptosis by 4-Formyloximeetylidene-3-Hydroxyl-2-Vinyl-Deuterio-Porphynyl(IX)-6-7-Diaspartic Acid (ATX-S10). Biochem \& Anal Biochem S2-001. doi:10.4172/2161-1009.S2-001

Page 3 of 7

(DNA ladders) were visualized using a UV transilluminator. The size of the DNA fragments was determined by comparison with DNA molecular weight markers (100 bp DNA ladder; Invitrogen, Carlsbad, CA, USA).

\section{Measurement of caspase- 3 activity}

Caspase-3 activity was assayed by a using the specific fluorogenic substrate Ac-DEVD-AFC (MBL, Tokyo, Japan). Treated cells were washed with $50 \mathrm{mM}$ PBS ( $\mathrm{pH} 7.4)$ and then resuspended in buffer containing $50 \mathrm{mM}$ Tris-HCL (pH 7.4), $1 \mathrm{mM}$ EDTA, and $10 \mathrm{mM}$ EGTA. The cell lysates were then centrifuged at $800 \times \mathrm{g}$ for $5 \mathrm{~min}$, and the supernatant was incubated with $50 \mu \mathrm{M}$ of peptide substrate at $37^{\circ} \mathrm{C}$ for 2 hours. The formation of 7-amino-4-trifrluoromethylcoumarin was measured using a fluorescence spectrophotometer (F-3000, Hitachi, Japan) with excitation at $400 \mathrm{~nm}$ and emission at $505 \mathrm{~nm}$. The enzyme activity measured just prior to each experiment was used as the control. The caspase activity was expressed as the ratio of released 7-amino-4trifrluoromethylcoumarin for the experimental condition compared to the untreated control.

\section{Electron spin resonance (ESR) measurements}

Ultrasonically induced nitroxide production in the presence and absence of ATX-S10 was measured by ESR spectroscopy in an airsaturated aqueous solution of $50 \mathrm{mM}$ TMPone in the presence and absence of oxygen scavengers. The $\mathrm{pH}$ of the solutions was adjusted to 9.0 with $50 \mathrm{mM}$ PBS. At appropriate time points, samples were taken for ESR measurement and place in glass capillary tubes with an inner diameter of 1.1-1.2 mm, a wall thickness of $0.2 \mathrm{~mm}$, and a length of $75 \mathrm{~mm}$ (Allied Corporation Fisher Scientific, Pittsburgh, PA, USA). The ESR spectra were recorded using a JEOL JES-FE3XG X-band spectrometer (JEOL Ltd., Tokyo, Japan) operating at a $100 \mathrm{kHz}$ modulation frequency and at a $9.26 \mathrm{GHz}$ microwave frequency. The modulation amplitude of the magnetic field was set at $1.0 \times 10-4 \mathrm{~T}$, and the microwave power was $10 \mathrm{~mW}$. The concentration of the produced nitroxide was determined by comparison with the peak-to-peak ESR signal amplitude of a $1 \mathrm{mM}$ 2,2,6,6-tetramethyl-4-piperidone- $\mathrm{N}$-oxyl solution. The ratio of the amplitude to the nitroxide concentration was also verified by comparison with the peak-to-peak ESR signal amplitude of a $1 \mathrm{mM}$ 2,2,6,6-tetramethyl-4-piperidol- $\mathrm{N}$-oxyl solution.

\section{Statistical analysis}

The results were expressed as the mean \pm standard deviation (S.D.). The values were compared by 1 way analysis of variance with 0.05 as the minimum level of significance.

\section{Results}

\section{Cell damage}

We first exposed HL-60 cells to an ultrasound $(6 \mathrm{~W} / \mathrm{cm} 2)$ in the presence and absence of $80 \mu \mathrm{M}$ ATX-S10 and examined their integrity by staining with Trypan blue. Figure 3 shows the fraction of unstained HL-60 cells vs. the duration of exposure. The results show that the unstained (intact) fraction decreased exponentially with the duration of exposure. Following exposure to ultrasound for $3 \mathrm{~min}$ in the presence and absence of ATX-S10, the fraction of unstained cells was $80 \%$ and $56 \%$, respectively. ATX-S10 alone did not cause cell damage.

\section{Morphological changes}

We next assessed the induction of apoptosis by examining the morphology of the cells with a phase contrast microscope after a 4-hours incubation with no addition, $80 \mu \mathrm{M}$ ATX-S10 alone, ultrasound alone $(6 \mathrm{~W} / \mathrm{cm} 2)$, and ultrasound in the presence of ATX-S10. There was no significant morphological change in the cells treated with either ATX-S10 alone (Figure 4a,b) or ultrasound alone (Figure 4c). In contrast the combination of ultrasound and ATX-S10 clearly caused membrane blebbing and cell shrinkage (Figure 4d).

\section{Induction of apoptosis}

From the phase contrast microscope images, we calculated the fractions of apoptotic cells and plotted them vs. time (Figure 5). Under all conditions, the fraction of apoptotic cells was less than $2 \%$

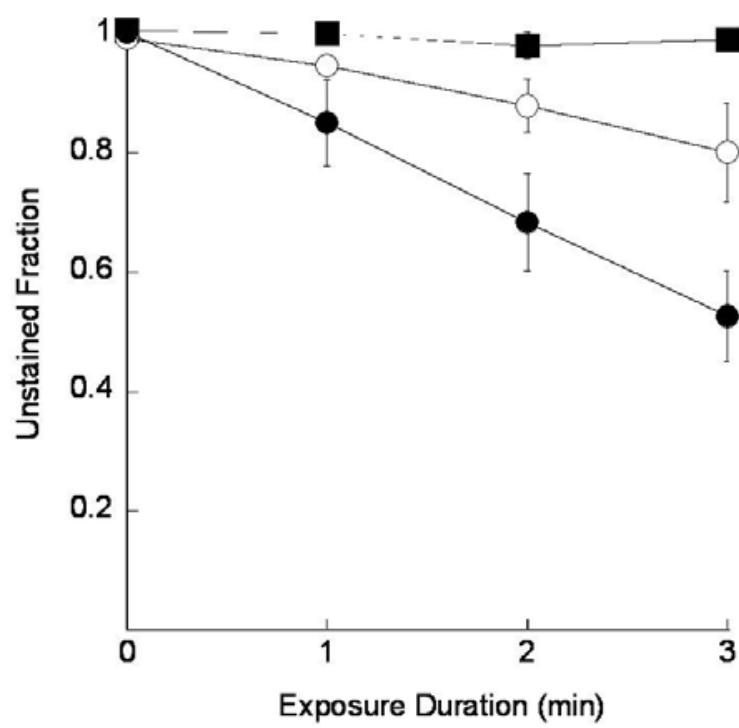

Figure 3: Fraction of HL60 cells not stained with Trypan blue following ultrasonic exposure in the presence and absence of ATX-S10. $\mathbf{m}, 80 \mu \mathrm{M}$ ATXS10 alone; $\circ$, ultrasound alone; •, $80 \mu \mathrm{M}$ ATX-S10 + ultrasound. Values represent the means \pm S.D. of four independent experiments.

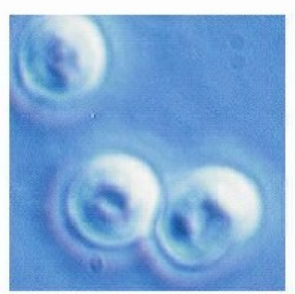

a) Control

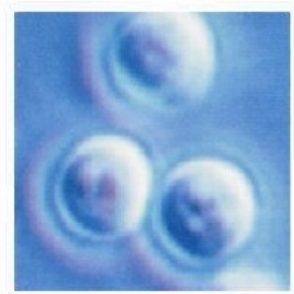

b) AT-XS10 alone

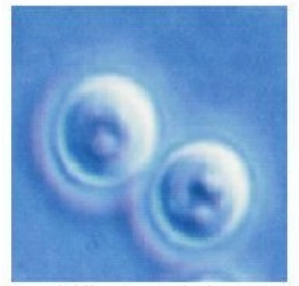

c) Ultrasound alone

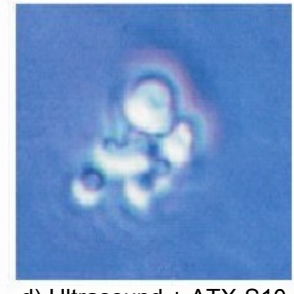

d) Ultrasound + ATX-S10
Figure 4: Analysis of cellular morphology by phase contrast microscopy after a 4-h incubation under the following conditions: (a) control, (b) $80 \mu \mathrm{M}$ ATX-S10 alone, (c) ultrasound alone, and (d) $80 \mu \mathrm{M}$ ATX-S10 + ultrasound. 
Citation: Yumita N, Iwase Y, Nishi K, Ikeda T, Fukai T, et al. (2011) Involvement of Reactive Oxygen Species in Sonodynamically Induced Apoptosis by 4-Formyloximeetylidene-3-Hydroxyl-2-Vinyl-Deuterio-Porphynyl(IX)-6-7-Diaspartic Acid (ATX-S10). Biochem \& Anal Biochem S2-001. doi:10.4172/2161-1009.S2-001

Page 4 of 7

immediately following initiation of the treatment. In cells exposed to ultrasound in the presence of ATX-S10, there was a significant increase

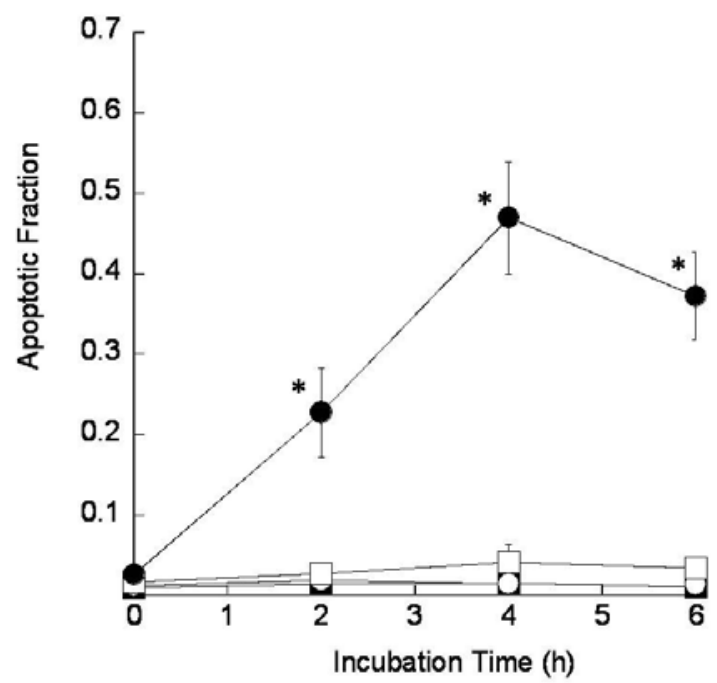

Figure 5: Fraction of apoptotic HL-60 cells after a 3-min exposure to ultrasound in the presence and absence of ATX-S10. $\Upsilon$, control;, $80 \mu \mathrm{M}$ ATX-S10 alone; $\circ$, ultrasound alone; $\bullet, 80 \mu \mathrm{M}$ ATX-S10 + ultrasound. Values represent the means \pm S.D. of four independent experiments. The asterisk symbol indicates significant difference from untreated control at $\mathrm{P}<0.05$.

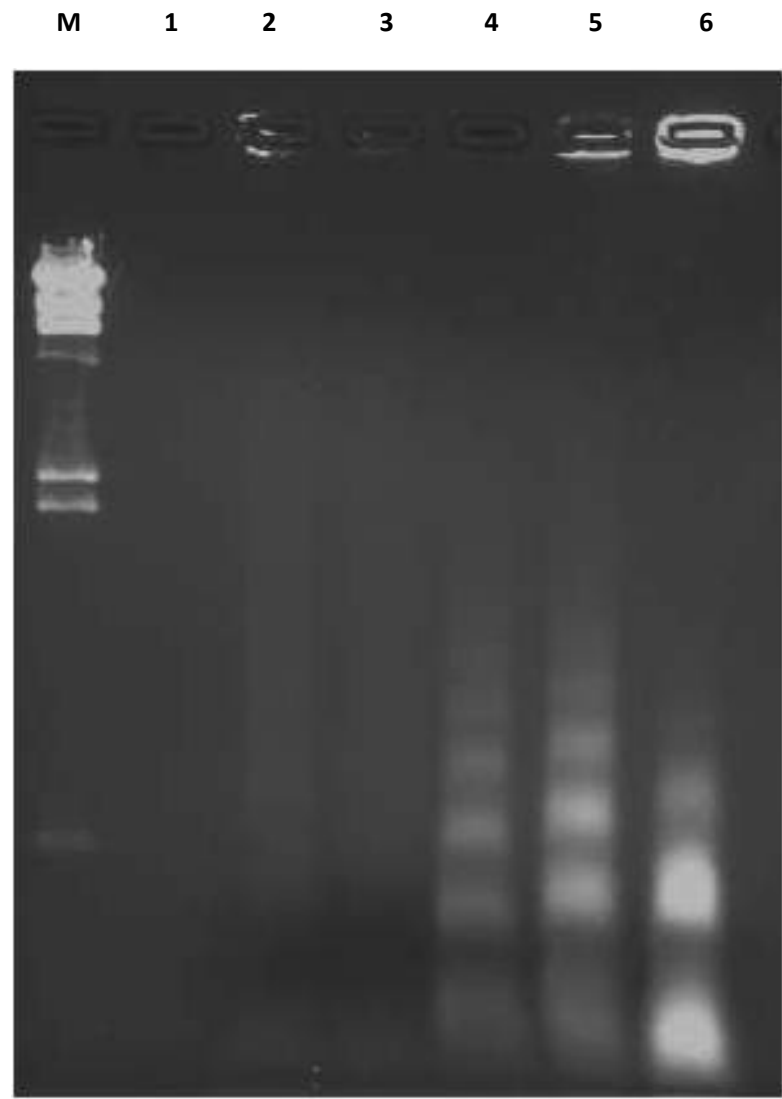

Figure 6: Nitroxide generation in an air-saturated solution of $50 \mathrm{mM}$ TMPone during exposure to ultrasound in the presence and absence of ATX-S10. $\Upsilon$, control; $₫, 80 \mu \mathrm{M}$ ATX-S10 alone; o, ultrasound alone; $\bullet, 80 \mu \mathrm{M}$ ATX-S10 + ultrasound. Values represent the means \pm S.D. of four independent experiments. in the fraction of apoptotic cells that increased with time. The fraction of apoptotic cells reached a maximum after $4 \mathrm{~h}$ and then decreased. A significant increase in the apoptotic fraction was not observed in cells exposed to ultrasound or ATX-S10 alone.

\section{DNA fragmentation}

To further explore the induction of apoptosis, we performed agarose gel electrophoresis of DNA samples from the HL60 cells (Figure 6). A characteristic DNA ladder in HL-60 cells was observed 4 hours after the exposure to ultrasound in the presence of $80 \mu \mathrm{M}$ ATX-S10 (lane 6). An obvious DNA ladder was not observed in cells exposed to ultrasound alone (lane 2) or ATX-S10 alone (lane 3).

\section{Caspase- 3 activation}

To investigate whether caspases are activated by sonodynamic treatment in HL-60 cells, we measured the enzymatic activity of caspase-3 using a fluorescent peptide substrate (Figure 7). We found that the activity of caspase- 3 increased, reached a maximum after 4 hours, and then decreased in cells treated with ultrasound in the presence of $80 \mu \mathrm{M}$ ATX-S10. An increase in caspase-3 activity was not observed in cells treated with ultrasound or ATX-S10 alone.

\section{Nitroxide generation}

The reactive oxygen species by ESR and spin trapping technique to determine whether reactive oxygen species including singlet oxygen and hydroxyl radicals participate in the induction of apoptosis by ultrasound. Figure 8 shows the amounts of nitroxide ultrasonically generated in air-saturated aqueous solutions of $50 \mathrm{mM}$ TMPone with and without ATX-S10 under the same acoustic conditions as employed in the cellular experiments. The nitroxide levels were determined from the ESR signal amplitudes and plotted vs. the insonation time. The amount of ultrasonically generated nitroxide increased linearly with the insonation time. ATX-S10 at a concentration of $80 \mu \mathrm{M}$ enhanced the rate approximately three-fold. Nitroxide generation was not observed with ATX-S10 alone.

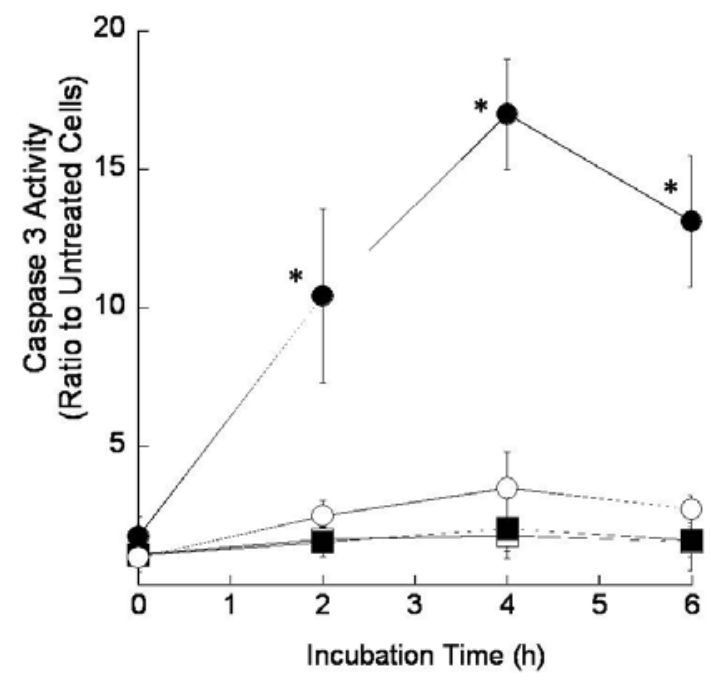

Figure 7: DNA ladder formation in HL-60 cells $4 \mathrm{~h}$ after exposure to ATX-S10 and/or ultrasound. Lane M, DNA size markers; Lane 1, control; Lane 2, $80 \mu \mathrm{M}$ ATX-S10 alone; lane 3, ultrasound alone; Lane 4, $10 \mu \mathrm{M}$ ATX-S10 + ultrasound Lane 5, $40 \mu \mathrm{M}$ ATX-S10 + ultrasound, Lane 6, $80 \mu \mathrm{M}$ ATX-S10 + ultrasound. 
Citation: Yumita N, Iwase Y, Nishi K, Ikeda T, Fukai T, et al. (2011) Involvement of Reactive Oxygen Species in Sonodynamically Induced Apoptosis by 4-Formyloximeetylidene-3-Hydroxyl-2-Vinyl-Deuterio-Porphynyl(IX)-6-7-Diaspartic Acid (ATX-S10). Biochem \& Anal Biochem S2-001. doi:10.4172/2161-1009.S2-001

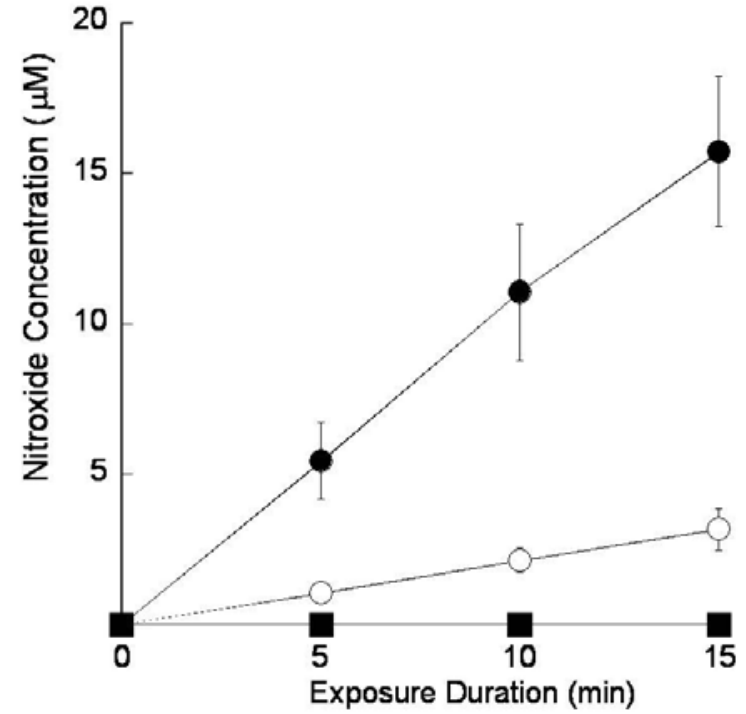

Figure 8: Caspase-3 activities in HL-60 cells after a 3-min exposure to ultrasound in the presence and absence of ATX-S10. $\Upsilon$, control; $\mathbf{m}, 80 \mu \mathrm{M}$ ATX-S10 alone; $\circ$, ultrasound alone; $\bullet, 80 \mu \mathrm{M}$ ATX-S10 + ultrasound. Values represent the means \pm S.D. of four independent experiments. The asterisk symbol indicates significant difference from untreated cells at $\mathrm{P}<0.05$.

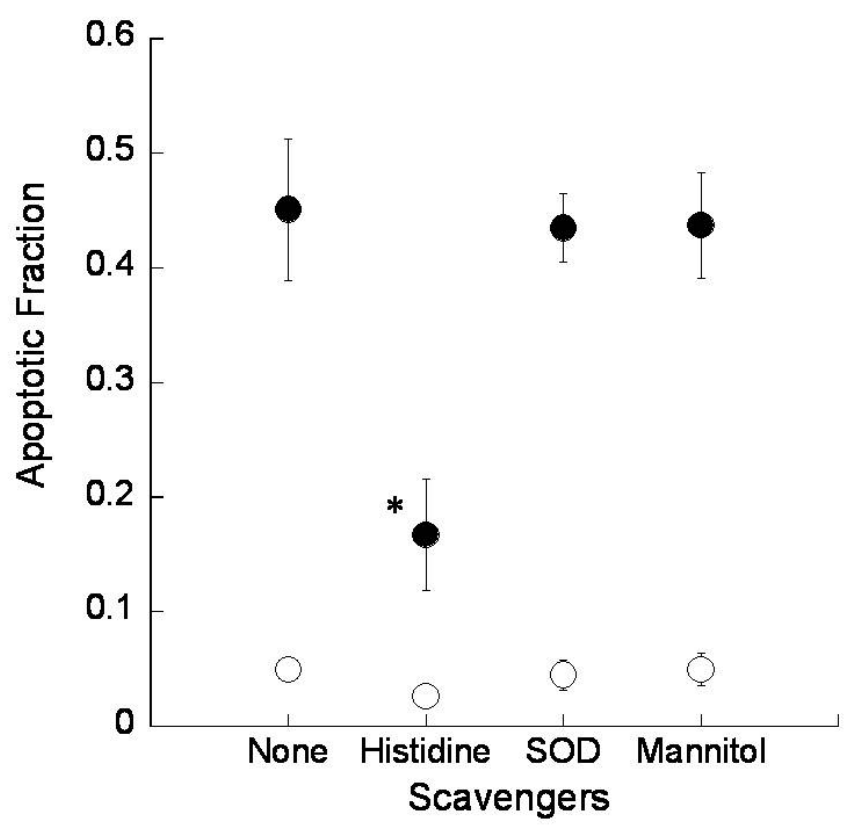

Figure 9: Effect of reactive oxygen scavengers on ultrasonically induced apoptosis in the presence $(\bullet)$ and absence $(0)$ of $80 \mu \mathrm{M}$ ATX-S10. Values represent the means \pm S.D. of four independent experiments. The asterisk symbol indicates significant difference from no scavenger treatment at $P<0.05$.

\section{Effect of reactive oxygen scavengers}

To determine whether reactive oxygen species including singlet oxygen and hydroxyl radicals participate in the induction of apoptosis by ultrasound, we examined the effect of reactive oxygen scavengers ( 10 $\mathrm{mM}$ histidine, $100 \mu \mathrm{g} / \mathrm{ml} \mathrm{SOD}$, and $100 \mathrm{mM}$ mannitol) on the fraction of cells showing morphological changes associated with apoptosis as well as on the caspase- 3 activity and the production of nitroxide

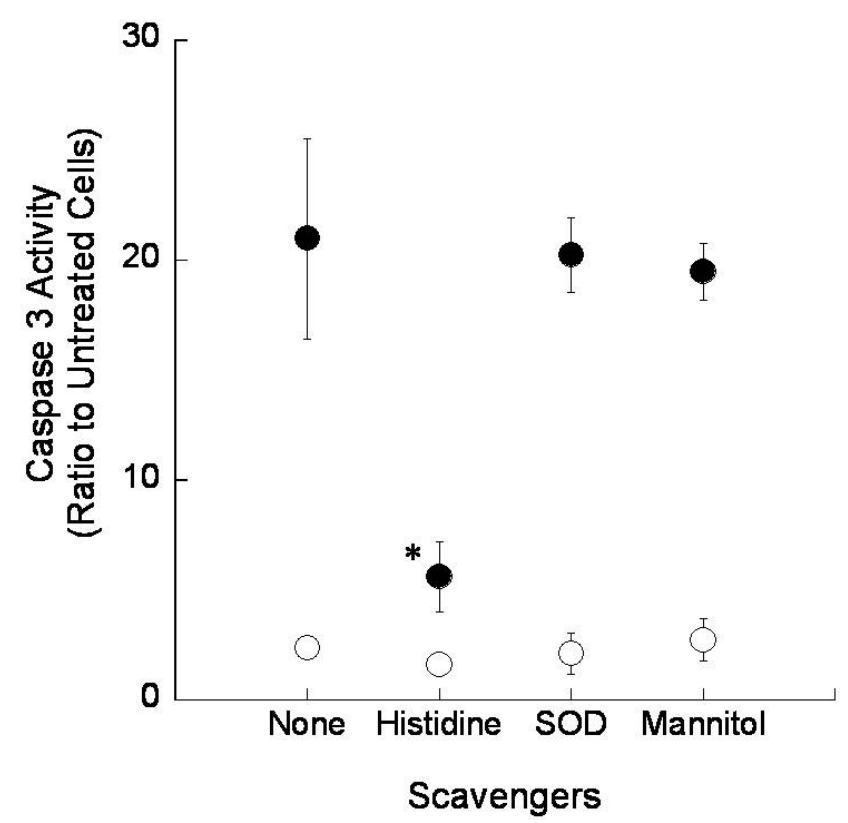

Figure 10: Effect of reactive oxygen scavengers on ultrasonically induced caspase-3 activation in the presence $(\bullet)$ and absence (o) of $80 \mu \mathrm{M}$ ATX-S10. Values represent the means \pm S.D. of four independent experiments. The asterisk symbol indicates significant difference from no scavenger treatment at $\mathrm{P}<0.05$.

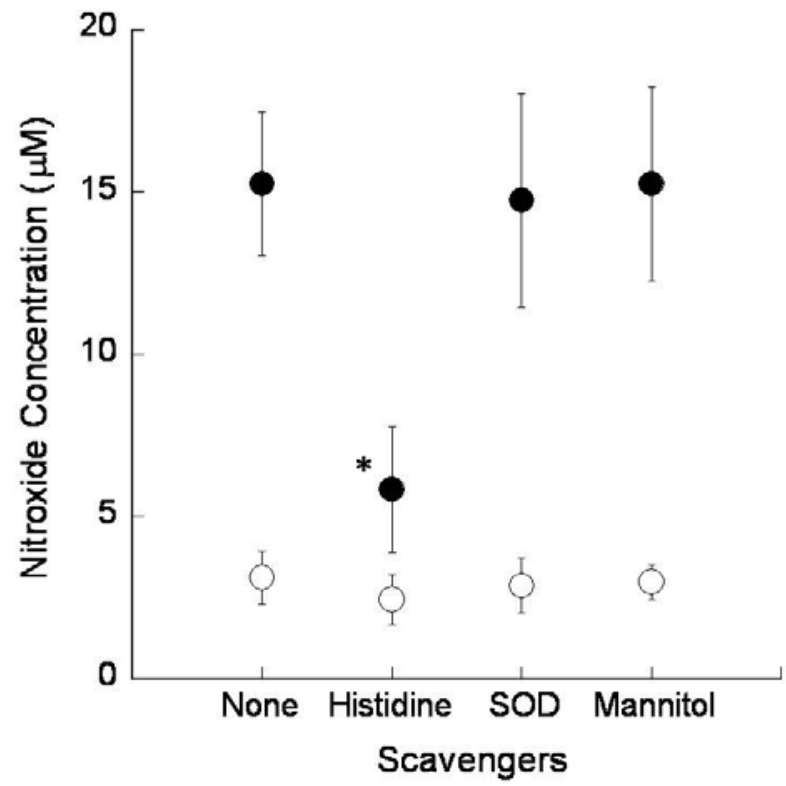

Figure 11: Effect of reactive oxygen scavengers on ultrasonic nitroxide generation in the presence $(\bullet)$ and absence $(\circ)$ of $80 \mu \mathrm{M}$ ATX-S10. Values represent the means \pm S.D. of four independent experiments. The asterisk symbol indicates significant difference from no scavenger treatment at $\mathrm{P}<0.05$.

(Figures 9-11). Histidine significantly reduced the apoptosis induction, caspase- 3 activation, and nitroxide generation caused by exposure to ultrasound in the presence of ATX-S10. In contrast, SOD and mannitol did not effect these measurements.

\section{Discussion}

In our initial morphological studies, we found that ultrasonically 
Citation: Yumita N, Iwase Y, Nishi K, Ikeda T, Fukai T, et al. (2011) Involvement of Reactive Oxygen Species in Sonodynamically Induced Apoptosis by 4-Formyloximeetylidene-3-Hydroxyl-2-Vinyl-Deuterio-Porphynyl(IX)-6-7-Diaspartic Acid (ATX-S10). Biochem \& Anal Biochem S2-001. doi:10.4172/2161-1009.S2-001

Page 6 of 7

induced apoptosis is greatly enhanced by ATX-S10. Specifically, we clearly observed membrane blebbing and cell shrinkage when cells were treated with a combination of ultrasound and ATX-S10, whereas significant morphologic changes were not observed in the cells exposed to either ultrasound alone or ATX-S10 alone. The apoptotic fraction in the cells after the combination treatment was higher than both treatments with ultrasound alone and with ATX-S10 alone by more than an order of magnitude. These results clearly demonstrated the synergistic effect between ATX-S10 and ultrasound, namely the sonodynamic effect with PF, on the apoptosis.

The fragmentation of DNA at linker regions between nucleosomes into fragments that are multiples of 180-200 base pairs in length is a hallmark of apoptosis [17]. Using agarose gel electrophoresis, we found that ultrasonic exposure in the presence of ATX-S10 resulted in the formation of a characteristic DNA ladder. This was not observed immediately after exposure (data not shown) but clears after the 4 hours incubation, indicating that DNA fragmentation was caused by an enzymatic process rather than by direct sonochemical damage to the HL-60 cells.

Caspase-3 is an important enzyme required for the execution of the final phase of apoptosis, and it is active in cells undergoing apoptotic death [19]. We observed a significant activation of caspase-3 after treatment with a combination of ultrasound and ATX-S10. This activation of caspase- 3 was associated with the induction of apoptosis. Both the apoptotic fraction and the activity of caspase- 3 gradually increased to a maximum after 4 hours and then decreased, suggesting that caspase- 3 acts as the executor caspase responsible for the induction of apoptosis by sonodynamic treatment, but how caspase- 3 was activated by sonodynamic treatment remains to be determined.

Like photodynamic reactions, sonodynamic reactions are classified as either type I or type II [27]. In type I reactions, the exited state of the sensitizer reacts with the substrate, whereas in type II reactions, it reacts with oxygen, yielding radicals, radical ions, or singlet oxygen. We observed a substantial enhancement of nitroxide generation in the presence of ATX-S10 and under sonodynamic conditions used in the cellular experiments. Studies on the effects of reactive oxygen scavengers and $\mathrm{D} 2 \mathrm{O}$ substitution on ultrasonically induced cell damage and on ultrasonic generation of reactive oxygen species suggest that singlet oxygen is the most important reactive oxygen species for the sensitizer effect of porphyrins [13]. We therefore examined the inhibitory effect of reactive oxygen scavengers on the fraction of sonodynamically induced apoptotic cells, caspase- 3 activation, and nitroxide generation.

Hiraoka et al. [28] hypothesized that sonodynamically induced cell killing was more likely due to certain mechanical stress such as augmentation of physical disruption of cellular membrane by sensitizers. However, the significant reduction by histidine in both ultrasonically induced apoptosis and caspase-3 activation clearly suggests that some ultrasonically generated active species, which can be deactivated by histidine, stimulated the apoptotic signaling pathways through caspase- 3 activation.

The tested scavengers included histidine, which is known to scavenge singlet oxygen and possibly hydroxyl radicals, $100 \mathrm{mM}$ mannitol, a concentration that should scavenge both photodynamically and sonodynamically induced hydroxyl radicals and SOD, which catalyzes the elimination of superoxide radicals [13,29]. Histidine caused a significant reduction in ultrasonically induced apoptosis, caspase- 3 activation, and nitroxide generation, suggesting that singlet oxygen is more important than hydroxyl radicals or superoxide in the induction of apoptosis by ultrasound and ATX-S10. These results also suggest that reactive oxygen species stimulate apoptotic signaling pathways via caspase- 3 activation.

Misik and Riesz [30] suggest another possible mechanism of sonosensitizer-derived free radicals as mediators of sonodynamically induced cell damage. They proposed that sonosensitization is due to the chemical activation of sonosensitizers in the close vicinity of hot collapsing cavitation bubbles to form sensitizer-derived free radicals. These carbon-centered free radicals react with oxygen to form peroxyl and alkoxyl radicals.

Histidine can potentially deactivate the exited state of ATX-S10 while either mannitol or superoxide dismutase cannot. Therefore, the effectiveness of histidine in contrast with the ineffectiveness of the other two can also be explained by the hypothesis that the observed sonodynamic enhancement of apoptosis by ATX-S10 was induced by reactive oxygen species such as singlet oxygen, and sensitizer-derived free radicals. Singlet oxygen could be generated because the cell susupension was air-saturated in the ultrasonic exposure, at least when it was started. These results also suggest that reactive oxygen species such as singlet oxygen and sensitizer-derived free radicals stimulate apoptotic signaling pathways via caspase-3 activation [26].

In conclusion, we demonstrated sonodynamically induced apoptosis in HL-60 cells, as evidenced by morphological changes, DNA ladder formation, and caspase-3 activation. The significant reduction by histidine in the number of sonodynamically induced apoptotic cells, caspase-3 activation, and nitroxide generation suggests that ultrasonically generated singlet oxygen is an important mediator of sonodynamically induced apoptosis. Further studies on the mechanism of sonodynamically induced apoptosis should provide useful information for the improvement of sonodynamic tumor treatment. The present series of experiments was carried out using a single cell line. The investigation of other cell lines is necessary to examine the the possibility of in vivo induction of apoptosis. The results reported in this paper may be preliminary in the senses above, but they significantly support the possibility of in vivo induction of apoptosis by sonodynamic treatment using ATX-S10. To expand our results, an in vivo experiment using solid tumor is under a way to examine more physiological effects following sonodynamic treatment, which may provide important information in sonodynamically induced apoptosis.

\section{Acknowledgement}

This work was supported, in part, by a Grant-in-Aid for Scientific Research (C) from Japan Society for the Promotion of Science to Nagahiko Yumita (No 22500444)

\section{References}

1. Kremkau FW (1979) Cancer therapy with ultrasound: a historical review. J Clin Ultrasound 7: 287-300.

2. Lele PP, Nussbaum GH (1982) Physical aspect of hyperthermia. American Institute of Physics, New York.

3. Rosenthal I, Sostaric ZJ, Riesz P (2004) Sonodynamic therapy- a review of the synergistic effects of drugs and ultrasound. Ultrason Sonochem 11: 349-363.

4. Yu T, Wang Z, Mason TJ (2004) A review of research into the uses of low level ultrasound in cancer therapy. Ultrason Sonochem 2: 95-103.

5. Umemura S, Kawabata K, Sasaki K, Yumita N (1996) Recent advances in sonodynamic approach to cancer therapy. Ultrason Sonochem 3: 187-191.

6. Tachibana K, Uchida T, Hisano S, Morioka E (1997) Eliminating adult T-cell leukaemia cells with ultrasound. Lancet 349: 325. 
Citation: Yumita N, Iwase Y, Nishi K, Ikeda T, Fukai T, et al. (2011) Involvement of Reactive Oxygen Species in Sonodynamically Induced Apoptosis by 4-Formyloximeetylidene-3-Hydroxyl-2-Vinyl-Deuterio-Porphynyl(IX)-6-7-Diaspartic Acid (ATX-S10). Biochem \& Anal Biochem S2-001. doi:10.4172/2161-1009.S2-001

7. Abe H, Kuroki M, Tachibana K, Li T, Awasthi A (2002) Targeted sonodynamic therapy of cancer using a photosensitizer conjugated with antibody against carcinoembryonic antigen. Anticancer Res 3: 1575-1580.

8. Umemura S, Yumita N, Nishigaki R (1993) Enhancement of ultrasonically induced cell damage by a gallium-porphyrin complex, ATX70. Jpn J Cancer Res 84: 582-588.

9. Yumita N, Umemura S, Nishigaki R (2000) Ultrasonically induced cell damage enhanced by photofrin II: mechanism of sonodynamic activation. In Vivo 14 $425-429$.

10. Yumita N, Nishigaki R, Umemura S (2000) Sonodynamically induced antitumor effect of photofrin II on colon 26 carcinoma. J Cancer Res Clin Oncol 126: 601-606

11. Yumita N, Sasaki K, Umemura S, Nishigaki R (1996) Sonodynamically induced antitumor effect of a gallium-porphyrin complex, ATX-70. Jpn J Cancer Res 87: 310-316.

12. Yumita N, Umemura S (2003) Sonodynamic therapy with photofrin II on AH130 solid tumor. Pharmacokinetics, tissue distribution and sonodynamic antitumora efficacy of photofrin II. Cancer Chemother Pharmacol 51: 74-178.

13. Umemura S, Yumita N, Nishigaki R, Umemura K (1990) Mechanism of cell damage by ultrasound in combination with hematoporphyrin. Jpn J Cancer Res 81: 962-966.

14. Nakajima S, Hayashi H, Sakata I (1993) New photosensitizer ATX-S10 having Type I photoreaction. J Clin Exp Med 164: 187

15. Yamamoto J, Hirano T, Li S, Koide M, Kohno E, et al. (2005) Selective accumulation and strong photodynamic effects of a new photosensitizer ATX-S10.Na (II), in experimental malignant glioma. Int J Oncol 27: 1207-1213.

16. Yumita N, Nishigaki R, Sakata I, Nakajima S, Umemura S (2000) Sonodynamically induced antitumor effect of 4-formyloximethylidene-3hydroxy-2-vinyl-deuterio-porphynyl (IX) - 6,7-diaspartic acid (ATX-S10). Jpn J Cancer Res 91: 255-260.

17. Thompson CB (1995) Apoptosis in the pathogenesis and treatment of disease. Science 267: 1456-1462.

18. Schemp CM, Simon-Haarhaus B, Termeer CC Simon JC (2001) Hypericin photo-induced apoptosis involves the tumor necrosis factor-related apoptosisinducing ligand (TRAIL) and activation of caspase-8. FEBS Lett 493: 26-30.
19. Vantieghem A, Assefa Z, Vandenabeele P, Declercq W, Courtois S, et al (1998) Hypericin-induced photosensitization of HeLa cells leads to apoptosis or necrosis. Involvement of cytochrome c and procaspase-3 activation in the mechanism of apoptosis. FEBS Lett 440:19-24.

20. Feril LB Jr, Kondo T, Takaya K, Riesz P (2004) Enhanced ultrasound-induced apoptosis and cell lysis by a hypotonic medium. Int J Radiat Biol 80: 165-175.

21. Feril LB Jr, Tsuda Y, Kondo T, Zhao QL, Ogawa R, et al. (2004) Ultrasoundinduced killing of monocytic U937 cells enhanced by 2,2'-azobis(2amidinopropane) dihydrochloride. Cancer Sci 95: 181-185.

22. Feril LB Jr, Kondo T, Ogawa R, Zhao QL (2003) Dose-dependent inhibition of ultrasound-induced cell killing and free radical production by carbon dioxide. Ultrason Sonochem 10: 81-84.

23. Ashush H, Rozenszajn LA, Blass M, Barda-Saad M, Azimov D, et al. (2000) Apoptosis induction of human myeloid leukemic cells by ultrasound exposure. Cancer Res 60: 1014-1020.

24. Lagneaux L, de Meulenaer EC, Delforge A, Dejeneffe M, Massy M, et al. (2002) Ultrasonic low-energy treatment: a novel approach to induce apoptosis in human leukemic cells. Exp Hematol 30: 1293-1301.

25. Feril LB Jr, Kondo T, Zhao QL, Ogawa R, Tachibana K, et al. (2003) Enhancement of ultrasound-induced apoptosis and cell lysis by echo-contrast agents. Ultrasound Med Biol 29: 331-337.

26. Yumita N, Okudaira K, Momose Y, Umemura S (2010) Sonodynamically induced apoptosis and reactive oxygen generation by gallium-porphyrin complex, ATX70. Cancer Chemother Pharmacol 66:1071-1078

27. Foote CS (1991) Definition of type I and type II photosensitized oxidation Photochem Photobiol 54: 659.

28. Hiraoka W, Honda H, Feril LB Jr, Kudo N, Kondo T (2006) Comparison between sonodynamic effect and photodynamic effect with photosensitizers on free radical formation and cell killing. Ultrasonic Sonochemistry 13: 535-542.

29. Goldstein S, Czapski G (1984) Mannitol as $\mathrm{OH}$ scavenger in aqueous solutions and biological systems. Int J Radiat Biol 46: 725-729.

30. Misik V, Riesz P (2000) Free radical intermediates in sonodynamic therapy. Ann N Y Acad Sci 899: 335-348.
This article was originally published in a special issue, Reactive Oxygen Species: Oxidative damage \& Pathogenesis handled by Editor(s). Dr. Yong Wu, University of California, USA; Dr. M Salman Khan, Integral University, India 